Exiting Shelter: An Epidemiological Analysis of Barriers and Facilitators for Families Author(s): Linda Weinreb, Debra J. Rog, Kathryn A. Henderson

Source: The Social Service Review, Vol. 84, No. 4 (December 2010), pp. 597-614

Published by: The University of Chicago Press

Stable URL: http://www.jstor.org/stable/10.1086/657108

Accessed: 09/02/2011 10:15

Your use of the JSTOR archive indicates your acceptance of JSTOR's Terms and Conditions of Use, available at http://www.jstor.org/page/info/about/policies/terms.jsp. JSTOR's Terms and Conditions of Use provides, in part, that unless you have obtained prior permission, you may not download an entire issue of a journal or multiple copies of articles, and you may use content in the JSTOR archive only for your personal, non-commercial use.

Please contact the publisher regarding any further use of this work. Publisher contact information may be obtained at http://www.jstor.org/action/showPublisher?publisherCode=ucpress.

Each copy of any part of a JSTOR transmission must contain the same copyright notice that appears on the screen or printed page of such transmission.

JSTOR is a not-for-profit service that helps scholars, researchers, and students discover, use, and build upon a wide range of content in a trusted digital archive. We use information technology and tools to increase productivity and facilitate new forms of scholarship. For more information about JSTOR, please contact support@jstor.org. 


\title{
Exiting Shelter: An Epidemiological Analysis of Barriers and Facilitators for Families
}

\author{
Linda Weinreb \\ University of Massachusetts \\ Debra J. Rog \\ Westat and the Rockville Institute \\ Kathryn A. Henderson \\ Westat
}

\begin{abstract}
This study examines the role of individual- and family-level factors in predicting the length of shelter stays for homeless families. Interviews were conducted with all families exiting one of six emergency family shelters in Worcester, Massachusetts, between November 2006, and November 2007. Analyses, using an ordinary least squares regression model, find that families with a positive alcohol or drug screen in the year prior stay 85 days longer than those without a positive screen; families leaving shelter with a housing subsidy stay 66 days longer than those leaving without a subsidy. Demographic factors, education, employment, health, and mental health are not found to predict shelter stay duration. Consistent with prior research, housing resources relate to families' time in shelter; with the exception of a positive substance abuse screen, individual-level problems are not related to their time in shelter. Efforts to expand these resources at the local, state, and national levels are a high priority.
\end{abstract}

One-third of the homeless population in the United States is composed of families. In 2008, 159,000 families and 360,000 children experienced homelessness. This represents a 9 percent increase over the prior year (U.S. Department of Housing and Urban Development 2009). For families, a homeless spell commonly means staying in a family shelter for anywhere from one night to as long as 18 months (Culhane et al. 2007). 
Little research investigates pathways out of homelessness and into residential stability. Much of the literature on homeless families focuses on pathways into homelessness, describing the characteristics and needs of these families (Rog et al. 1995; Bassuk et al. 1996; Shinn et al. 1998). In the few studies that examine residential stability, receipt of subsidies emerges as the most common factor in facilitating homeless families' stability (Stretch and Kreuger 1992; Wong, Culhane, and Kuhn 1997; Shinn et al. 1998; Rog and Buckner 2007). Most studies find that race, ethnicity (Wong et al. 1997), and family structure (i.e., families of young women who recently gave birth; Metraux and Culhane 1999) are correlated with risk for additional homeless episodes, but the results demonstrate mixed support of the relationship of stability with such other individual factors as depression, domestic violence, and substance abuse (Metraux and Culhane 1999; Bassuk, Perloff, and Dawson 2001; Rog and Buckner 2007).

Some guidance emerges from the literature on adult individuals' transitions into and out of homelessness. Past studies recognize the heterogeneity of the population and varying patterns of homelessness (Sosin 2003). These studies note that both the diverse characteristics of the homeless population and varying patterns of homelessness can allow for more targeted programs and policies (Sosin 2003). Other research documents the association of chronic, individual homelessness with some form of disability or other behavioral health barrier that limits successful exit from homelessness and entry into housing stability (Culhane et al. 2007). Most homeless adults, however, maintain a stable exit after a short period of homelessness (Culhane et al. 2007). The literature on adult homelessness points to the limitations of stratification and individual-level explanations. It suggests the usefulness of a more complex, situational explanation that emphasizes the interaction of resource issues with other life circumstances and, indirectly, with personal characteristics. Such an effort may help to explain most individuals' transitions into and out of homelessness (Sosin 2003). This explanation notes the roles that key life events may play in homelessness (e.g., convergence of job loss, high medical expenses, and inadequate supportive relationships). It may also consider the interaction of less extreme resource problems with personal circumstances (e.g., conflicted relationships with family; Sosin 2003).

Recent work by Dennis Culhane and colleagues (2007), however, suggests that, for families, personal circumstances may have less bearing on the timing of shelter exits than policy and program factors. Culhane and associates' (2007) analysis, based on four states' administrative data and patterned after previous research involving single homeless adults (Kuhn and Culhane 1998), attempts to understand the distinctions among short-term, episodically, and chronically homeless families. This research suggests that families with long shelter stays do not demonstrate more intensive service needs, disability, or unemployment than those 
with short shelter stays; however, at least one critique of the study (Bassuk 2007) notes that families' experiences may not be adequately captured in studies that use the same methodology with families as with adults. Information on use of inpatient psychiatric services and other measures available through administrative data sources are likely not sensitive to the nature of the mental health conditions that families contend with (e.g., depression and posttraumatic stress). Administrative data also may not capture such family circumstances as credit problems, children's needs, legal difficulties, and other issues. Family strengths, such as employment and employability, may also escape notice in administrative data sets but could potentially relate to homeless exit time. Whereas the study by Culhane and colleagues (2007) makes an important contribution to the understanding of different subgroups of homeless families, the results require corroboration and elaboration to fully capture the range of families' needs and the extent to which they relate to their homelessness experience (Karnas 2007).

In fact, interest in developing a typology of homeless families provides the impetus for the work by Culhane and associates (2007), as well as that by Debra Rog, C. Scott Holupka, and Lisa Patton (2007). The major goal of such a classification system is to improve understanding of homeless families' characteristics, service needs, and interaction with human services systems. Another goal is to clarify how those features relate to the dynamics of shelter use. Understanding the factors that explain variations in shelter exits may inform improvements to the allocation of resources and expedite families' exit.

The current study is designed to extend this earlier work. It attempts to understand the extent to which individual- and family-level factors predict length of shelter stay. This study collected data directly from families at the point of exit from shelter. For families, exiting shelter is often synonymous with exiting an episode of literal homelessness, unlike for homeless adult individuals, for whom a shelter exit may not result in an exit from homelessness. The majority of families, when exiting emergency shelter, go to some type of housing arrangement, including doubled-up arrangements, market rate housing, subsidized housing, and transitional housing. Understanding the factors that relate to time in exit from emergency shelter is, therefore, relevant to study for families and will allow for more effective service matching at the front end of homelessness to families' needs and specific situations.

\section{Study Design and Methods}

\section{Sample}

Of the 278 families entering the six emergency family shelters in Worcester, Massachusetts, between November 2006 and November 2007, 91 
percent $(n=253)$ consented to be contacted for interviews upon their exit. Families were identified through the shelters and the Central Massachusetts Housing Alliance, the local agency contracted by Massachusetts Department of Transitional Assistance (DTA) to provide housing search services to all homeless families. During the study period, five shelters contracted with the state's DTA and had criteria for determining a family's eligibility to receive shelter; the sixth shelter offers families community beds (i.e., not contracted through the DTA) and provides services similar to those offered by the DTA contract shelters. ${ }^{1}$

During the study period, 184 families exited the six shelters and were eligible for the exit analysis. Of these families, 76 percent $(n=139)$ completed an exit interview, and administrative data provide exit dates for all of these families. As the respondent pool is primarily female and the analysis focuses on factors (such as mental health and substance abuse) that likely are sensitive to gender differences, the final sample for this analysis excludes the small number of father-only families $(n=6)$. Families that were asked to leave the shelter by staff $(n=12)$ also are excluded, as the interest in this analysis lies in factors that explain voluntary exits. The resulting sample is composed of 121 families. ${ }^{2}$

\section{Data Collection}

Trained female interviewers conducted in-person interviews with mothers in the sampled families. Interviews generally took place in a private shelter office, in the family's new housing arrangement, or at the study's research office within the University of Massachusetts Medical School. Each interview took approximately 60-75 minutes. Interviews were conducted either 2 weeks prior to or 2 weeks following shelter exit. The interview protocol was modified in light of results from a pilot test conducted with six families. Spanish-language versions of the instrument were developed and administered by bilingual interviewers.

Participants received $\$ 20$ per hour for their participation in the interviews. They also received provisions for transportation and child care. The study received approval from the University of Massachusetts Medical School Institutional Review Board.

\section{Variables}

The study's main dependent variable is the number of days in emergency shelter. Shelter entry and exit dates are obtained from the study participants. They are confirmed (or completed, in cases of missing dates) with data from the shelter and the Central Massachusetts Housing Alliance. For families with consecutive stays in multiple shelters (either in Worcester or in multiple areas), the number of days in a shelter stay is computed using the date of entry into the first shelter.

The interview included items on demographics, family composition, 
household income, and debt (i.e., housing-related debt, including back rent, back utilities, and money owed to housing authority; as well as other sources of debt, e.g., credit cards and cell phone bills), the mothers' education level, employment, health, mental health, experience of trauma, substance abuse, and criminal and legal involvement. Information was gathered on whether conflict occurred in the family's household before the current homeless episode, making it impossible to stay. Standardized measures are used for a number of these domains. A 6month residential history is assessed through the Residential FollowBack Calendar (New Hampshire-Dartmouth Psychiatric Research Center 1995). Additional questions cover experiences with homelessness over the lifetime and during the 2 years prior to survey.

Health functioning is assessed with four selected questions from the physical component summary (PCS) in the SF-8 Health Survey (Ware et al. 2001). The PCS is standardized, and scores range from zero to 100 (average is 50). Scores less than 40 (i.e., one standard deviation or more below the mean) are considered to fall within the clinical range.

Three measures of mental health status are used. The GAD-7, a sevenitem scale, screens for general anxiety disorder (Spitzer et al. 2006). Scores between 10 and 14 represent moderate anxiety; scores of 15 or greater represent severe anxiety.

The Patient Health Questionnaire (PHQ-9) is a nine-item instrument that makes criteria-based diagnoses of depression (Spitzer et al. 1999). Items in the questionnaire are concordant with the fourth edition of the Diagnostic and Statistical Manual of Mental Disorders (American Psychiatric Association 1994). Scores of 10-14 represent moderate depression, scores of 15-19 represent moderately severe depression, and scores of 20 or greater represent severe depression. Because the interviews were conducted in nonclinical, community-based settings, the interview did not include the ninth item, which concerns suicidal ideation (for this omission in other studies, see Kroenke and Spitzer [2002]).

The Maternal Health-SF-8 Mental Component Summary (MCS; Ware et al. 2001) is derived from the four items measuring mental health functioning. Like the PCS, the MCS is standardized. Scores range from zero to 100 . The average score is 50 , and scores less than 40 (i.e., one standard deviation or more below the mean) are considered to fall within the clinical range. Also measured are the number of times a woman was hospitalized for psychiatric or emotional problems in her lifetime and whether she ever attempted suicide.

The TWEAK screening test (Chan et al. 1993; Russell 1994), a fivequestion test originally designed to screen pregnant women for harmful drinking habits, is employed to screen for alcohol use. ${ }^{3}$ Also used to screen for harmful drinking in general household samples (Chan et al. 1993), the test is found to be highly predictive of alcohol abuse and dependence in racially mixed populations (Bradley et al. 1998; Cherpitel 
1999). The maximum score on the test is 7 points; a total score of 2 or more on the test indicates harmful drinking and the need for further evaluation (O'Connor and Whaley 2003). A version of the Drug Abuse Screening Test (DAST), the DAST-10, is a brief iteration of the 28-item DAST (Skinner 1982). The DAST-10 is designed to identify drug-abuserelated problems in the year prior to interview (Cocco and Carey 1998; French et al. 2001). Scores of 3 or greater represent moderate or severe problems related to drug use.

Exposure to traumatic events is assessed using a four-item trauma index that is based on the Life Stressors Checklist-Revised (LSC-R) developed by Jessica Wolfe and colleagues (1996). The test was adapted by the Homeless Families Study (Sacks et al., forthcoming). The index consists of items measuring lifetime exposure, exposure as an adult, exposure as a child, and exposure within the 6 months prior to survey, to physical trauma and violence, sexual assault, and sexual abuse. Trauma symptom severity is measured with the Posttraumatic Symptom Severity Scale (PSS; Foa et al. 1997), a 17-item self-report instrument that assesses the three diagnostic criteria for post-traumatic stress disorder (PTSD), as well as the severity of the symptoms. Scores range from zero to 51; higher scores indicate more stress.

Families exiting shelter were also asked a series of questions about where they were going after exiting. These questions investigate housing type and location.

\section{Analysis}

Descriptive analyses provide a summary of the study population's characteristics. Ordinary least squares regression is used to regress selected independent variables on length of shelter stay. ${ }^{4}$ Selection of the initial set of predictor variables is based on theory and findings from past research. Before the final selection of variables, the authors examined bivariate correlations and checked the variables for normality. When appropriate, the authors transformed highly skewed continuous variables into dichotomous measures (e.g., the number of mental health hospitalizations to a measure of whether the subject was ever hospitalized for mental health issues). To select the predictor variables for domains in which multiple factors (i.e., mental health, substance abuse, and trauma) could potentially be related to the outcome of interest, the authors use those predictors that are identified as most theoretically relevant based on the literature (Rog and Buckner 2007). However, a number of sensitivity tests determined whether alternate measures of similar concepts (i.e., has a chronic or ongoing health problem vs. physical health summary score) have different effects on the dependent variable. The results are largely consistent across measures within the various domains. 
The resulting set of predictors includes the specific shelter the family was staying in, mother's age, mother's race (nonwhite or white), mother's education level (high school diploma or general equivalency diploma [GED] and more than high school), number of children in the household under 18 years, whether there are other adults in the household, the SFPCS score, MCS score, whether the mother reported a previous suicide attempt, whether the subject was previously hospitalized for mental health, reported past exposure to trauma, positive screen to the TWEAK, and the positive screen for the DAST-10. Additional predictors include the amount of housing-related debt; conflict in last household that made it impossible to stay; previous conviction, jail, or prison stay; previous homelessness; whether the head of household was employed for at least 1 year in the past; total household income in the 30 days prior to the interview; and whether the family has a housing subsidy.

Sensitivity tests were conducted before the final regression. Each category of variables (e.g., demographics) was regressed on the dependent variable, independent of the other measures. Results for these tests are similar to those for the full models.

\section{Results}

\section{Sample Characteristics}

The vast majority of sampled families are composed of single mothers and their children (table 1). On average, sampled families are reported to include two children under the age of 18 . Approximately 25 percent of the mothers report that they have a child who lives away from them. One-third (34 percent) of mothers are white, 40 percent are Hispanic, and 25 percent are black. Only 13 percent of mothers report that they are married, but 25 percent report that another adult lives in the household (these adults may be partners, siblings, or parents). Mothers, on average, were 30 years old at the time of the interview, and the majority reportedly has at least a high school diploma or GED. Most (95 percent) report that they have been employed in the past. The reported mean household income during the 30 days prior to the interview is $\$ 696$. With respect to entitlements, 64 percent report that their families receive benefits from the Temporary Assistance for Needy Families program, and 94 percent report receiving food stamps. Only 17 percent of mothers report that they were employed just prior to entering shelter, and over a third (37 percent) report that they are unable to work. Sampled families are similar to those described in prior studies of homeless families in terms of mothers' average age, number and ages of children, percent that are members of minority groups, employment history, and income levels, though they reported a somewhat greater likelihood of having a GED or high school diploma (Rog and Buckner 2007). Families are similar in 
Table 1

Worcester Shelter Family Characteristics at Exit

\begin{tabular}{|c|c|}
\hline & $\%$ or Mean \\
\hline \multicolumn{2}{|l|}{ Demographic characteristics: } \\
\hline Age (years) & $29.60(8.5)$ \\
\hline \multicolumn{2}{|l|}{ Race $(\%)$ : } \\
\hline White & 34 \\
\hline Black & 25 \\
\hline Hispanic & 40 \\
\hline Other race & 9 \\
\hline Married (\%) & 13 \\
\hline \multicolumn{2}{|l|}{ Family composition: } \\
\hline No. of children under 18 & $2.07(1.4)$ \\
\hline Percentage with another adult in household & 25 \\
\hline No. of other adults in household & $1.10(.6)$ \\
\hline Percentage with child living away & 25 \\
\hline Percentage with open DSS plan & 22 \\
\hline \multicolumn{2}{|l|}{ Education level $(\%)$ : } \\
\hline Less than high school diploma & 33 \\
\hline Finished high school or GED & 35 \\
\hline More than high school diploma & 33 \\
\hline \multicolumn{2}{|l|}{ Current employment status at time of interview $(\%)$ : } \\
\hline Currently employed & 24 \\
\hline Unable to work & 37 \\
\hline \multicolumn{2}{|l|}{ Employment histories (\%): } \\
\hline Ever employed & 95 \\
\hline Employed for more than 1 year & 55 \\
\hline Employed prior to entering shelter & 17 \\
\hline Employed while in shelter & 17 \\
\hline \multicolumn{2}{|l|}{ Last place stayed $(\%)$ : } \\
\hline Stayed in own place & 19 \\
\hline Stayed in parent's place & 17 \\
\hline Stayed in doubled-up place & 55 \\
\hline Stayed in treatment facility & 2 \\
\hline Homeless prior to entering shelter & $\overline{6}$ \\
\hline \multicolumn{2}{|l|}{ Residential history (\%): } \\
\hline Previously homeless in last 2 years & 19 \\
\hline Previously homeless in lifetime & 50 \\
\hline Experienced conflicts in last household & 47 \\
\hline \multicolumn{2}{|l|}{ Health $(\%)$ : } \\
\hline Pregnant & 14 \\
\hline Fair or poor health & 37 \\
\hline Low physical health functioning (SF8-PCS) & 12 \\
\hline \multicolumn{2}{|l|}{ Mental health indicators $(\%)$ : } \\
\hline Attempted suicide & 23 \\
\hline Hospitalized for mental health & 24 \\
\hline Moderate or severe depression score (PHQ-9) & 36 \\
\hline Moderate or severe anxiety score (GAD-7) & 37 \\
\hline Low mental health functioning (SF8-MCS) & 14 \\
\hline Received mental health services in shelter* & 48 \\
\hline \multicolumn{2}{|l|}{ Substance abuse $(\%)$ : } \\
\hline Positive screen for alcohol abuse (TWEAK) & 33 \\
\hline Positive screen for drug abuse (DAST-10) & 16 \\
\hline Positive screen for alcohol or drug abuse & 36 \\
\hline Substance abuse contract with shelter & 23 \\
\hline Received substance abuse services in shelter ${ }^{\dagger}$ & 5 \\
\hline \multicolumn{2}{|l|}{ Physical and sexual abuse $(\%)$ : } \\
\hline Ever experienced trauma (LSC-R) & 64 \\
\hline $\begin{array}{l}\text { Experienced trauma in } 6 \text { months prior to } \\
\text { interview }\end{array}$ & 7 \\
\hline
\end{tabular}


Moderate or severe trauma symptoms (PSS) 34

$\begin{array}{ll}\text { Received trauma services in shelter } \ddagger & 49\end{array}$

Legal and criminal history $(\%)$ :

Convicted of a felony

Spent time in jail or prison because of a conviction

Currently dealing with legal problems 39

Debt:

Percentage with debt upon entering shelter

Mean amount of debt upon entering shelter $(\$)$

Median amount of debt upon entering shelter $(\$)$

Percentage with debt at time of interview

Mean amount of debt at time of interview (\$)

Median amount of debt at time of interview $(\$)$

Percentage with housing debt

Mean amount of housing debt $(\$)$

Median amount of housing debt $(\$)$

Income $(\$)$ :

Mean income in 30 days prior to interview

Median income in 30 days prior to interview

Benefits (\%):

Has a housing subsidy $\quad 42$

Receives TANF $\quad 64$

$\begin{array}{ll}\text { Receives food stamps } & 94\end{array}$

Receives WIC $\quad 61$

$\begin{array}{ll}\text { Receives school lunch } & 77\end{array}$

Receives day care vouchers $\quad 35$

Exit destinations (\%):

One's own apartment with a housing subsidy 39

$\begin{array}{ll}\text { One's own apartment without a housing subsidy } & 19\end{array}$

Doubled-up residence $\quad 8$

Transitional housing program 33

Other arrangement

Note. $-N=121$. Standard deviations are in parentheses. DSS $=$ Department of Social Services; SF8-PCS = SF-8 Health Survey Physical Component Summary; PHQ-9 = Patient Health Questionnaire-9 items; GAD-7 = Generalized Anxiety Disorder-7 questions; SF8-MCS = SF-8 Health Survey Mental Component Summary; TWEAK = Tolerance, Worried, Eye Opener, Amnesia, K/Cut Down; DAST-10 = Drug Abuse Screening Test-10 item; LSC-R = Life Stressors Checklist-Revised; PSS = Posttraumatic Symptom Severity Scale; GED $=$ General Equivalency Diploma; TANF = Temporary Assistance for Needy Families program benefits; WIC = Special Supplemental Nutrition Program for Women, Infants, and Children.

* Of those 52 with a moderate or severe mental health indicator.

$\dagger$ Of those 43 with a positive screen for alcohol or drugs.

$\ddagger$ Of those 41 with a moderate or severe trauma indicator.

terms of demographic factors (i.e., maternal age, family composition, racial composition) to housed low-income families headed by women in the same geographic area (Bassuk et al. 1996).

The results suggest that most families (72 percent) lived with parents or doubled up (i.e., with friends or family) prior to entering the shelter. About half the population ( 47 percent) cites conflicts in their last household as a reason for their current homelessness, and about 50 percent report at least one prior episode of homelessness.

On average, mothers score in the healthy range on both the mental health (MCS) and health functioning scales (PCS; score of 50 or 
greater). More than half (64 percent), however, report experiencing physical or sexual abuse, and 34 percent report moderate or severe trauma symptoms. About a fourth of the mothers report that they attempted suicide at some point (23 percent), and a similar percentage (24 percent) reports a prior hospitalization for a mental health reason; 15 percent report both. Thirty-six percent of the mothers are reported to have moderate or severe depression, and 37 percent report moderate or severe anxiety. Fourteen percent report a low mental health functioning score. Of those mothers with one or more of these three mental health indicators, 48 percent report receiving mental health services while in shelter. Results from the TWEAK and DAST-10 assessments suggest that over one-third of mothers (36 percent) have positive screens for current alcohol (33 percent) or drug (16 percent) problems, and nearly a fourth (23 percent) of mothers report that they have a substance abuse contract with the shelter. A substance abuse contract is an agreement between the head of household and the shelter. The head of household agrees to abstain from substance use, but the contract is not a treatment plan, per se. There is substantial variation in the ways that shelters use such contracts. For example, shelters differ both in terms of which families participate in establishing a contract and in the extent to which the contrast encourages participation in treatment. None of the shelters uses a contract that mandates treatment. Only 5 percent of women with a positive drug or alcohol screen report receiving substance abuse services while in shelter.

Thirty-nine percent of mothers report that their families have legal problems, including housing-related legal problems (e.g., eviction, property damage), and other legal problems (e.g., bankruptcy, divorce, custody issues, and criminal charges); much smaller percentages report that they have a felony conviction (9 percent) or past incarceration spells (prison or jail; 11 percent). The vast majority of families (83 percent) report having had one or more debts upon shelter entrance. Participants indicate that these debts are the same amount at the time of their exit as at the time of shelter entrance. Over half (52 percent) report that they have housing debt; the average reported housing debt is $\$ 1,182$. Mothers indicate that the top sources of debt include unpaid utilities, cable bills, and cell phone charges.

A sizable percentage of the sampled families reports that they exit to their own apartment with a housing subsidy (39 percent) or to a transitional housing program (33 percent). Smaller percentages report exiting to their own apartment without a housing subsidy (19 percent) or to a doubled-up situation, such as a parent's or partner's residence (8 percent). Very few families, less than 2 percent, report exiting to another arrangement such as a substance abuse treatment center or a mental health facility. 
Table 2

Mean Days in Shelter by Shelter

\begin{tabular}{lrcrcr}
\hline & $N$ & $\begin{array}{c}\text { Mean Days } \\
\text { in Shelter }\end{array}$ & \multicolumn{1}{c}{ SD } & Minimum & Maximum \\
\hline Shelter A & 19 & $258.16^{*}$ & 163.15 & 56 & 831 \\
Shelter B & 43 & 221.77 & 131.99 & 33 & 548 \\
Shelter C & 24 & 174.75 & 109.12 & 31 & 414 \\
Shelter D & 17 & 193.59 & 95.48 & 75 & 472 \\
Shelter E & 9 & $119.22^{*}$ & 88.50 & 21 & 259 \\
Shelter F & 9 & $120.44^{*}$ & 72.83 & 15 & 212 \\
Total & 121 & 197.24 & 128.17 & 15 & 831 \\
\hline
\end{tabular}

$* p<.05$.

\section{Explaining Length of Shelter Stay}

Table 2 displays data on the number of days families spend in shelter. Overall, the average reported shelter stay for sampled families is a little more than 6 months (197.24 days), though there is wide variation by family. Eleven percent of the families report staying less than 2 months (59 days or fewer), whereas 20 percent report staying over 10 months (314 days or more), with nearly half of those (9 percent of the total sample) staying over a year. Because the lengths of shelter stays are subject to shelters' distinct policies and practices, either stated or unstated, it is important to understand how average stays vary across shelters. The results suggest that there are differences among the shelters, though the differences are not statistically significant. Two shelters, shelters $\mathrm{E}$ and $\mathrm{F}$, are found to have average stays of about 4 months (about 120 days), whereas the average stay in shelter $\mathrm{A}$ is found to be longer than 8 months (258.16 days). Stays at the other three shelters are estimated to average between 6 and 7 months (174.75-221.77 days).

Table 3 presents the results for the ordinary least squares equations modeling length of shelter stay for families that exited shelter. The model is estimated to explain 45 percent of the variance in the dependent variable. Among the families of mothers with a positive alcohol or drug screen in the 12 months prior to interview, shelter stays are estimated to be 85 days longer than the stays of families whose mother does not have a positive screen. Those who report leaving shelter with a housing subsidy are estimated to stay 66 days longer than those who exit without a subsidy. The results suggest that the number of children in the household is positively related to the length of shelter stay. Having another adult in the household is found to be negatively associated with the length of shelter stay. The findings suggest that age, race, education, current or historical measures of health and mental health, criminal history, conflict in the last household, monthly income, and whether one has a work history of a year or more are not statistically significant predictors of length of stay. 
Table 3

Predictors of Time to Shelter Exit

\begin{tabular}{|c|c|c|}
\hline & $\beta$ & SE \\
\hline Intercept & 129.96 & 100.16 \\
\hline \multicolumn{3}{|l|}{ Shelter (D is reference): } \\
\hline Shelter A & 69.98 & 39.52 \\
\hline Shelter B & 41.19 & 33.80 \\
\hline Shelter C & -15.00 & 37.23 \\
\hline Shelter E & -31.59 & 46.57 \\
\hline Shelter F & -16.66 & 49.90 \\
\hline \multicolumn{3}{|l|}{ Demographic characteristics: } \\
\hline Age & .68 & 1.28 \\
\hline Nonwhite (white is reference) & -26.70 & 24.66 \\
\hline High school diploma or higher & -21.16 & 24.33 \\
\hline No. of children & $17.10 *$ & 8.39 \\
\hline Has another adult in household & $-52.46^{*}$ & 25.77 \\
\hline \multicolumn{3}{|l|}{ Health and well-being: } \\
\hline Summary physical health score & -.89 & 1.07 \\
\hline Summary mental health score & 1.24 & .92 \\
\hline Attempted suicide & 35.17 & 31.77 \\
\hline Ever hospitalized for mental health & 46.20 & 31.74 \\
\hline Ever experienced trauma & -48.15 & 25.55 \\
\hline Positive alcohol or drug screen & $85.44 * * *$ & 23.62 \\
\hline \multicolumn{3}{|l|}{ Barriers: } \\
\hline $\begin{array}{l}\text { Amount of housing debt (in hun- } \\
\text { dreds of dollars) }\end{array}$ & $-1.12^{*}$ & .52 \\
\hline Conflicts in last household & 14.42 & 21.42 \\
\hline Criminal history & 33.13 & 35.61 \\
\hline Previously homeless & -23.70 & 21.11 \\
\hline \multicolumn{3}{|l|}{ Assets: } \\
\hline Worked for at least 1 year in past & 32.89 & 23.71 \\
\hline $\begin{array}{l}\text { Total monthly income (in hun- } \\
\text { dreds of dollars) }\end{array}$ & -4.79 & 2.44 \\
\hline Has a housing subsidy & $66.25 * *$ & 21.81 \\
\hline$R^{2}$ & .45 & \\
\hline
\end{tabular}

\section{Discussion}

This study provides an important opportunity to understand the factors related to the length of stay in family shelters and adds to the literature in a number of ways. First, the study sample represents a census of families exiting shelter rather than a sample of convenience or a sample that has defined needs and is selected as part of an evaluation study. Second, the study focuses on needs and experiences of families as they exit shelter. Most of the literature on homeless families focuses either on pathways into homelessness or on housing, supports, and other factors associated with residential stability. Little research considers the factors associated with time spent in shelter and those that hinder or facilitate exit. Finally, this study builds on the work of Culhane and others (2007) by incorporating detailed and standardized measures of 
the range of needs and strengths that families have. These measures are included in order to examine the relationship of these variables to shelter length of stay.

Overall, the findings suggest that few individual-level variables have predictive value, alone or together. Interestingly, the two main predictors of shelter stay, having a positive alcohol or drug screen and exiting with a housing subsidy, seem to suggest that multiple forces are at work. Families headed by a mother with a positive alcohol or drug screen are found to stay statistically significantly longer (nearly 3 months longer) than those headed by mothers whose screen is not positive. There may be several explanations for this. Mothers who are using substances may be less able to find housing on their own and may not have family or friends willing to take them. It is also possible that shelter providers do not actively encourage a mother to exit until she is engaged in a treatment program. They may believe that the shelter stay provides an opportunity for families to get their needs met and to become stable before returning to their own housing.

The results concerning housing subsidies suggest the possibility that families hold out in shelter until a subsidy becomes available. About 42 percent of the families in the sample report that they exited shelter with a housing subsidy, and the majority (97 percent) moved to their own apartment (3 percent $[n=5]$ that had a subsidy chose to move to a doubled-up situation rather than an apartment with the subsidy). The estimates suggest that they exit, on average, nearly 2 months later than other sampled families. Anecdotal evidence provided to the authors by shelter workers suggests that families remain in shelter, and are often believed to enter shelter in the first place, in order to obtain a housing subsidy. Prior studies report that policies in some locales require a family to have an extended shelter stay before they will grant the family a housing subsidy (Wong et al. 1997). The wait for housing subsidies can be quite substantial, however, and the costs of using shelters as holding places are high; the system incurs monetary costs, and the family incurs instability. In addition, using shelters in this way likely extends unnecessarily the length of stays for families that may have relatively few barriers to exit (Culhane et al. 2007). However, given the strong relationship between housing stability and having a subsidy (Wong et al. 1997; Shinn et al. 1998; Rog and Buckner 2007), the financial cost of an extended shelter stay may be offset by savings realized through reductions in the rates of future homeless episodes (Wong et al. 1997). Despite this, study results suggest the need for strategies that provide early housing support to families.

Other variables that are found to predict length of stay include the number of children in the household, the number of adults in the household, and the amount of housing debt. The number of children can provide a barrier to exiting shelter because it can be challenging to find 
affordable housing with the bedrooms needed for large families. This finding is consistent with earlier research (Wong et al. 1997). The results suggest that the number of adults in a household can act as a protective factor. Prior research on residential stability also finds that, among families with incomes at or below 50 percent of the federal poverty level, having one or more other adults (in addition to the household head) helps keep the family in stable housing (Rog et al. 2007). It is possible that having another adult in the household contributes to income levels, thus improving the chances of a quick exit from shelter. Another adult may add tangible resources, such as child care or transportation, resources that may aid in job or housing search activities by the other adult. Other adults may also provide emotional support. All of these contributions may hasten the family's shelter exit. Alternatively, families with more than one adult in the household may be separated while in shelter; they may therefore look desperately for alternatives to shorten their shelter stays.

Finally, the results suggest that housing debt is negatively associated with the length of shelter stay, with longer stays observed among those families with less housing debt. This relationship is difficult to explain. It may represent families that have some type of subsidized housing and no source of income. Such conditions might make it necessary for these families to stay in shelter long enough to receive a subsidy.

What are the implications of these findings? First, much as it is difficult to predict which families will become homeless, it is difficult to predict which families will exit homelessness early and which will exit late. The results identify few individual-level predictors of shelter stay. Although families with substance use issues are an exception, the needs of families with long shelter stays are not found to be that distinct from the needs of families with shorter ones. This provides additional support for previous findings (Culhane et al. 2007), which suggest that families with long stays do not demonstrate more intensive service needs, disability, or unemployment than those with shorter stays. The estimated relationship between subsidy receipt and length of stay suggests that families' length of time in shelter is less a function of their needs and characteristics than of resource factors.

Second, the observed relationship between substance use and shelter stay is consistent with prior work and warrants further study. In contrast to prior studies that measure the presence of substance use disorder, this study measures substance-use-related vulnerability and need for further evaluation. Although this measure lacks the specificity of other measures of disorder, it is likely to have more sensitivity, identifying both the range of individuals likely to have substance use disorders and those at risk for such disorders. Measures that examine risk of substance use and problem substance use correlate well with clinical measures and 
can predict relevant concerns that relate to functioning (Schmidt, Weisner, and Wiley 1998).

Prior studies find that substance use among low-income women, and particularly those who are homeless, is associated with housing instability. Much like results in this study, those findings relate to difficulty exiting homelessness and to prolonged episodes of homelessness (Gregoire 1996; Zlotnick, Tam, and Robertson 2003). One reason for the association between substance abuse and prolonged housing instability may be that homeless women's substance use often goes untreated (Zima et al. 1996; Robertson, Zlotnick, and Westerfelt 1997; Zerger 2002). Among homeless women with a substance use disorder, only onethird report contact with any treatment services during the prior year (Zlotnick et al. 2003). A critical step in helping this subgroup of women to exit homelessness may be the development of accessible and effective ways to provide them with treatment for problem alcohol and drug use.

Finally, the possibility that families wait to leave shelter until they receive housing subsidies raises an important question: how might one broaden the nature of housing resources available to families? The resources spent on each sheltered family are not inconsequential. In cities like New York, shelter costs far exceed the cost of housing (Spellman et al. 2010). The current study's findings support the move by systems across the country to consider a broad range of supports for families, including shallow subsidies to time-limited subsidies, as well as other means of support, as a way to help families exit shelter (Rog and Buckner 2007).

A few limitations in this study should be noted. First, the study interviewed families at the point of shelter exit, and any background or history variables were measured at that time. Some recall issues and the experience of being in shelter could influence the data provided, especially the reports of residential history and knowledge of services. Further, there are potential trade-offs involved in using measures for current status at exit rather than measures for status at shelter entry that may have limited the predictive power of some variables. Some of the study measures (e.g., mental health functioning) may be less predictive of length of stay than they would be if assessed at shelter entry. Other measures, such as substance use, may be more accurately assessed at or near the time of exit than at the time of entry, because honest responses at the beginning of a shelter stay might increase families' vulnerability. Despite this concern, however, many of the study's variables measure lifetime and historical events and therefore are not dependent on the timing of the interview. Finally, the number of families tracked is relatively small, although the number represents a year's census in one middle-sized city. To achieve statistical significance, predictor variables' relationship with the length of stay must be relatively strong. 
In particular, if the sample includes a small subset of families with specific types of situations that affect their length of stay, the analyses are unlikely to recognize that group.

In summary, the current findings suggest that many of the factors previously found to relate to families' risk for homelessness (Shinn et al. 1998; Rog and Buckner 2007) do not predict duration of shelter stays. A positive substance abuse screen, however, is found to relate to the length of stay and warrants additional investigation. However, other individual-level factors are not statistically significant predictors of time to shelter exit for families. Although this study does not examine a range of program and policy factors, having a housing subsidy is estimated to be statistically significantly related to the length of time a family stays in shelter. The results of this study, bolstered by the strengths in measurement and sampling, add support to the finding that families' time in shelter likely has less to do with their constellation of needs and strengths than with the housing resources available. Efforts to broaden these resources therefore should be a priority at the local, state, and national levels.

\section{References}

American Psychiatric Association. 1994. Diagnostic and Statistical Manual of Mental Disorders, 4th ed. Washington, DC: American Psychiatric Association.

Bassuk, Ellen L. 2007. "Comment on Dennis P. Culhane et al.'s, 'Testing a Typology of Family Homelessness Based on Patterns of Public Shelter Utilization in Four U.S. Jurisdictions: Implications for Policy and Program Planning." Housing Policy Debate 18 (1): 29-41.

Bassuk, Ellen L, Jennifer N. Perloff, and Ree Dawson. 2001. "Multiply Homeless Families: The Insidious Impact of Violence." Housing Policy Debate 12 (2): 299-320.

Bassuk, Ellen L, Linda Weinreb, John C. Buckner, Angela Browne, Amy Salomon, and Shari S. Bassuk. 1996. "The Characteristics and Needs of Sheltered Homeless and Low-Income Housed Mothers." Journal of the American Medical Association 276 (8): 64046.

Bradley, Katharine, Jodie Boyd-Wickizer, Suzanne H. Powell, and Marcia L. Burman. 1998. "Alcohol Screening Questionnaires in Women: A Critical Review." Journal of the American Medical Association 280 (2): 166-71.

Chan, Arthur W. K., Edward A. Pristach, John W. Welte, and Marcia Russell. 1993. "Use of the TWEAK Test in Screening for Alcoholism/Heavy Drinking in Three Populations." Alcoholism: Clinical and Experimental Research 17 (6): 1188-92.

Cherpitel, Cheryl J. 1999. "Screening for Alcohol Problems in the U.S. General Population: A Comparison of the CAGE and TWEAK by Gender, Ethnicity, and Services Utilization." Journal of Studies on Alcohol 60 (5): 705-11.

Cocco, Karen M., and Kate B. Carey. 1998. "Psychometric Properties of the Drug Abuse Screening Test in Psychiatric Outpatients." Psychological Assessment 10 (4): 408-14.

Culhane, Dennis P., Stephen Metraux, Jung Min Park, Maryanne Schretzman, and Jesse Valente. 2007. "Testing a Typology of Family Homelessness Based on Patterns of Public Shelter Utilization in Four U.S. Jurisdictions: Implications for Policy and Program Planning." Housing Policy Debate 18 (1): 1-28.

Foa, Edna B., Laurie Cashman, Lisa Jaycox, and Kevin Perry. 1997. "The Validation of a Self-Report Measure of Posttraumatic Stress Disorder: The Posttraumatic Diagnostic Scale." Psychological Assessment 9 (4): 445-51.

French, Michael T., M. Christopher Roebuck, Kerry Anne McGeary, Dale D. Chitwood, and Clyde B. McCoy. 2001. "Using the Drug Abuse Screening Test (DAST-10) to 
Analyze Health Services Utilization and Cost for Substance Users in a CommunityBased Setting." Substance Use and Misuse 36 (6-7): 927-46.

$\rightarrow$ Gregoire, Thomas K. 1996. "Subtypes of Alcohol Involvement and Their Relationships to Exits from Homelessness." Substance Use and Misuse 31 (10): 1333-57.

Karnas, Fred. 2007. "Comment on Dennis P. Culhane et al.'s 'Testing a Typology of Family Homelessness Based on Patterns of Public Shelter Utilization in Four U.S. Jurisdictions: Implications for Policy and Program Planning.'” Housing Policy Debate 18 (1): $59-67$.

Kroenke, Kurt, and Robert L. Spitzer. 2002. "The PHQ-9: A New Depression Diagnostic and Severity Measure." Psychiatric Annals 32 (9): 509-15.

Kuhn, Randall, and Dennis P. Culhane. 1998. "Applying Cluster Analysis to Test a Typology of Homelessness by Pattern of Shelter Utilization: Results from the Analysis of Administrative Data." American Journal of Community Psychology 26 (2): 207-32.

Metraux, Stephen, and Dennis P. Culhane. 1999. "Family Dynamics, Housing, and Recurring Homelessness among Women in New York City Homeless Shelters." Journal of Family Issues 20 (3): 371-96.

New Hampshire-Dartmouth Psychiatric Research Center. 1995. Residential Follow-Back Calendar. Lebanon, NH: Dartmouth University Medical School.

O'Connor, Mary J., and Shannon E. Whaley. 2003. "Alcohol Use in Pregnant Low-Income Women.” Journal of Studies on Alcohol 64 (6): 773-83.

Robertson, Marjorie J., Cheryl Zlotnick, and Alex Westerfelt. 1997. "Drug Use Disorders and Treatment Contact among Homeless Adults in Alameda County, California." American Journal of Public Health 87 (2): 221-28.

Rog, Debra J., and John C. Buckner. 2007. "Homeless Families and Children." Paper presented at Toward Understanding Homelessness: The 2007 National Symposium on Homelessness Research, March 1-2, Washington, DC. http://aspe.hhs.gov/hsp/ homelessness/symposium $07 / \operatorname{rog} /$.

Rog, Debra J., C. Scott Holupka, and Lisa C. Patton. 2007. Characteristics and Dynamics of Homeless Families with Children. Report (contract no. 233-02-087 TK14). Washington, DC: U.S. Department of Health and Human Services, Office of the Assistant Secretary for Planning and Evaluation, Office of Human Services Policy.

Rog, Debra J., Kimberly L. McCombs-Thornton, Ariana Gilbert-Mongelli, M. Consuelo Brito, and C. Scott Holupka. 1995. "Implementation of the Homeless Families Program: 2; Characteristics, Strengths, and Needs of Participant Families." American Journal of Orthopsychiatry 65 (4): 514-28.

Russell, Marcia. 1994. "New Assessment Tools for Risk Drinking during Pregnancy: T-ACE, TWEAK, and Others." Alcohol Health and Research World 18 (1): 55-61.

Sacks, Joanne Y., Linda Weinreb, John Ford, Debra J. Rog, Lorraine McMullen, C. Scott Holupka, and Pamela Fischer. Forthcoming. "Trauma in the Lives of Homeless Mothers: Findings from the CMSH/CSAT Homeless Families Program." American Journal of Community Psychology.

Schmidt, Laura, Constance Weisner, and James Wiley. 1998. "Substance Abuse and the Course of Welfare Dependency." American Journal of Public Health 88 (11): 1616-22.

Shinn, Marybeth, Beth C. Weitzman, Daniela Stojanovic, James R. Knickman, Lucila Jiménez, Lisa Duchon, Susan James, and David Krantz. 1998. "Predictors of Homelessness among Families in New York City: From Shelter Request to Housing Stability." American Journal of Public Health 88 (11): 1651-57.

Skinner, Harvey. 1982. "The Drug Abuse Screening Test." Addictive Behaviors 7 (4): 36371.

Sosin, Michael R. 2003. "Explaining Adult Homelessness in the US by Stratification or Situation." Journal of Community and Applied Social Psychology 13 (2): 91-104.

Spellman, Brooke, Jill Khadduri, Brian Sokol, Josh Leopold, and Abt Associates. 2010. Costs Associated with First-Time Homelessness for Families and Individuals. Report, March. Washington, DC: U.S. Department of Housing and Urban Development.

Spitzer, Robert L., Kurt Kroenke, Janet B. W. Williams, and Bernd Löwe. 2006. "A Brief Measure for Assessing Generalized Anxiety Disorder: The GAD-7." Archives of Internal Medicine 166 (10): 1092-97.

Spitzer, Robert L., Kurt Kroenke, Janet B. W. Williams, and the Patient Health Questionnaire Primary Care Study Group. 1999. "Validation and Utility of a Self-Report Version 
of PRIME-MD: The PHQ Primary Care Study." Journal of the American Medical Association 282 (18): 1737-44.

Stretch, John J., and Larry W. Kreuger. 1992. "Five Year Cohort Study of Homeless Families: A Joint Policy Research Venture." Journal of Sociology and Social Welfare 19 (4): 73-88.

U.S. Department of Housing and Urban Development, Office of Community Planning and Development. 2009. The 2008 Annual Homeless Assessment Report to Congress. Report, July. Washington, DC: U.S. Department of Housing and Urban Development, Office of Community Planning and Development.

Ware, John E., Mark Kosinski, James E. Dewey, and Barbara Gandek. 2001. How to Score and Interpret Single-Item Health Status Measures: A Manual for Users of the SF-8 Health Survey. Lincoln, RI: Quality Metric.

Wolfe, Jessica, Rachel Kimerling, Pamela J. Brown, Kelly R. Chrestman, Karen Levin. 1996. "Psychometric Review of the Life Stressor Checklist-Revised." 198-200 in Measurement of Stress, Trauma, and Adaptation, edited by B. Hudnall Stamm. Lutherville, MD: Sidran.

Wong, Yin-Ling Irene, Dennis P. Culhane, and Randall Kuhn. 1997. "Predictors of Exit and Reentry among Family Shelter Users in New York City." Social Service Review 71 (3): 441-62.

Zerger, Suzanne. 2002. "Substance Abuse Treatment: What Works for Homeless People? A Review of the Literature." Report, June. National Health Care for the Homeless Council, Nashville, TN.

Zima, Bonnie T., Kenneth B. Wells, Bernadette Benjamin, and Naihua Duan. 1996. "Mental Health Problems among Homeless Mothers: Relationship to Service Use and Child Mental Health Problems." Archives of General Psychiatry 53 (4): 332-38.

Zlotnick, Cheryl, Tammy Tam, and Marjorie Robertson. 2003. "Disaffiliation, Substance Use, and Exiting Homelessness." Substance Use and Misuse 38 (3): 577-99.

\section{Notes}

The study was funded by the Commonwealth Medicine Division of the University of Massachusetts Medical School. We would like to thank Dorothy St. Cyr for providing oversight to a complex field operation, Amy Grassette and Lorna Chiasson for their input, and a committed team of interviewers. We would also like to acknowledge Grace Carmark, John Wagner, Julia Kehoe, Bob Pulster, Tina Brooks, Worcester shelter directors, and other officials and staff at the Massachusetts Department of Transitional Assistance for the insights provided throughout all phases of this study.

1. Eligibility criteria used by the five shelters include eligibility for emergency assistance. At that time, families were eligible for emergency assistance if the family's income was at or below 130 percent of the federal poverty line and the family's assets did not exceed $\$ 2,000$. The sixth shelter is a community shelter, with broader entry criteria; families from this sixth shelter contribute 7 percent to the sample.

2. The study is also interested in barriers to shelter exit for families. Therefore, families that reached 6 months in their shelter stay (the average shelter stay in central Massachusetts) were also interviewed. However, this article's analysis only includes those families that exited shelter during the study's data collection period.

3. The acronym TWEAK stands for Tolerance, Worried, Eye Opener, Amnesia, K/Cut Down.

4. Event history analysis was considered because it is typically the preferred analytic method for time-measured dependent variables and is the appropriate choice if there are censored cases (i.e., cases for which the date of shelter exit is unknown). It is not used for this analysis because there is complete information for the sample on the time of shelter exit. 